\title{
Life-cycle Seismic Costs Estimation and Seismic Insurance Model for Simple RC Buildings in Western China
}

\author{
Jian ZHU \\ Department of Civil and Hydraulic Engineering \\ Ning Xia University \\ Yin Chuan, China \\ e-mail: zhujian@nxu.edu.cn
}

\author{
Junhai ZHAO \\ School of Civil Engineering \\ Chang An University \\ Xi An, China \\ e-mail: zhaojh@cha.edu.cn
}

\author{
Jian ZHU \\ School of Civil Engineering \\ Chang An University \\ Xi An, China \\ e-mail: arrow66@163.com
}

\author{
Jianmin JIN \\ Earthquake Research Center \\ Guang Zhou University \\ Guang Zhou, China \\ e-mail: jinjm@gzu.edu.cn
}

\begin{abstract}
The estimation of annual average earthquake losses in life long period for simple reinforced concrete (RC) frames based stochastic method models is the focus of the article. An innovative assembly-based vulnerability methodology is firstly adopted for seismic loss estimation, that damage of the structure which connected into response of the structure under a given stochastic motions use nonlinear incremental dynamic analysis to estimate physical damage of columns and beams of buildings in a detailed. Description of the uncertainty of all parameters in research through appropriate probability distributions to reach quantification of the life-cycle seismic losses expected value. Moreover, the study is also to give the expected suggested insurance premium of RC buildings in China western high hazardous areas based Monte-Carlo stochastic simulation in its service lifetime.
\end{abstract}

Keywords-life-cycle seismic cost; stochastic ground motion models; assembly-based vulnerability; stochastic simulation; seismic insurance model

\section{INTRODUCTION}

The natural disasters such as earthquakes and hurricanes are known for their destructive impacts on human society. High seismic intensity regions and coastal regions are more vulnerability to natural disasters due to particular geographic location. Although it is not possible to completely avoid damage due to suddenly occurrence of disasters. It is however still possible to minimize their devastating effects by enhancing resilience in communities, that is, by reducing (1) system failure probability, (2) consequences of system failures, and (3) fee and time to recovery.

Performance-based earthquake engineering (PBEE) methodology was be developed by Pacific Earthquake Engineering Research (PEER) to reach the target in 2000. This approach involves combined numerical integration of all the conditional probabilities to propagate the uncertainties from one level of analysis to the next, resulting in probabilistic prediction of performance. The PBEE frame work consist of four steps, respectively is Hazard analysis, Structural analysis, Damage analysis and Loss analysis, The PBEE now has became future research basis spirit in civil engineering all of the world. Uncertainties are included and propagated through each step of the PBEE process[1].

At present for better approach above targets, many researchers further push the research performance-based engineering forward a great step over the entire life-cycle of the buildings. That is definitely exciting prospect but there also have several obstacles must be overcome at same time.

Earlier methodologies for seismic loss estimation mainly expressed seismic losses in terms of the global reliability characteristic of the structural system. Recent advances in PBEE quantify more appropriately repair cost, casualties, and downtime in relation to the structural or even on a detailed, component level (such as partitions, beams and columns) response, using seismic fragility curves to develop such a relationship. Nonlinear dynamic method as an more powerful analytical tool now accepted by many researchers in calculating seismic damage under a given earthquake excitation.

\section{LIFE-CYCLE SEISMIC LOSS METHODOLOGY}

In consideration of complexity and different regional characteristic about life-cycle seismic loss research, whole set of innovated life-cycle analysis procedures based stochastic probability have been raised in this article based past PBEE research results.

The methodology indeed expand research time to lifecycle of buildings based PBEE, so basically it also consist of four steps same as PBEE framework. The steps of the life cycle cost analysis in this research are shown in Fig.1. 


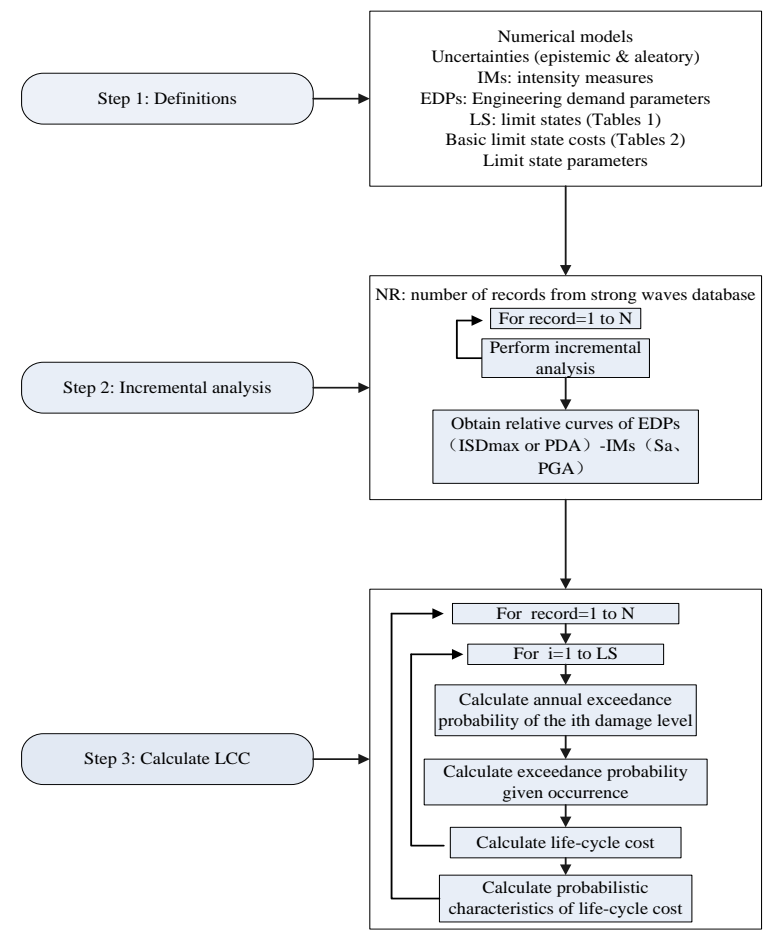

Figure 1. Flowchart of life-cycle cost estimation framework

The total cost $C_{\text {TOT }}$ of a structure may refer either to the design life period of a new building or to the remaining life period of an existing or retrofitting one. The cost can be expressed as a function of time and the design vector $\mathrm{s}$ as follows.

$$
C_{T O T}=C_{I N}(s)+C_{L S}(t, s)
$$

where $C_{I N}$ is the initial cost of a new or retrofitted structure, which is related to the material and labor cost for the construction of the buildings including, in the case of RC buildings, concrete, steel reinforcement labor cost for placement as well as the non-structural cost such as land fee, removal expenses etc. $C_{L S}$ is the present value of the limit state cost, that means damage and seismic loss of the RC buildings through different limit state to consider in this work. Damage, in the context of life-cycle cost assessment, refers no only to structural damage but also to non-structural damage. The latter including the case of architectural damage, mechanical, electrical and plumbing damage and also the damage of furniture, equipment and other contents. The maximum inter-storey drift has been considered as the structural damage response parameter. On the other hand, the maximum response floor acceleration is associated with the loss of contents, like furniture and equipment.

$$
C_{L S}^{i, \theta}=C_{d a m}^{i}+C_{c o n}^{i, \theta}+C_{r e n}^{i}+C_{i n c}^{i}+C_{i n j}^{i}+C_{f a t}^{i}
$$

$$
C_{L S}^{i, a}=C_{c o n}^{i, a}
$$

where $C_{d a m}^{i}$ is the damage repair cost, $C_{c o n}^{i, \theta}$ is the loss contents cost due to the structural damage $C_{r e n}^{i}$ is the loss of rental cost, $C_{i n c}^{i}$ is the income loss cost, $C_{i n j}^{i}$ is the cost of injuries and $C_{f a t}^{i}$ is the cost of human fatality. These cost components are related to the damage of the structural system. $C_{c o n}^{i, a}$ is the loss contents cost due to floor acceleration.

Based on a Poisson process model of the earthquake occurrences and an assumption that damaged buildings are immediately retrofitted to their original intact conditions after every seismic damage due to seismic attack.

$$
\begin{gathered}
C_{L S}=C_{L S}^{\theta}+C_{L S}^{a} \\
C_{L S}^{\theta}(t, s)=\frac{v}{\lambda}\left(1-e^{-\lambda t}\right) \sum_{i=1}^{N} C_{L S}^{i, \theta} \cdot P_{i}^{\theta} \\
C_{L S}^{a}(t, s)=\frac{v}{\lambda}\left(1-e^{-\lambda t}\right) \sum_{i=1}^{N} C_{L S}^{i, a} \cdot P_{i}^{a}
\end{gathered}
$$

where $C_{L S}^{\theta}$ and $C_{L S}^{a}$ is respectively the seismic loss cost for the ith limit state violation calculated based $I S D_{\max }$ and MFA according to Eqs.(4) and (5).The annual monetary discount rate $\lambda$ is taken constant and equal to $5 \%$.

The probabilities $P_{i}^{\theta}$ and $P_{i}^{a}$ of Eqs. (7) and (8) are calculated as follows:

$$
P_{i}^{D I}=P\left(D I>D I_{i}\right)-P\left(D I>D I_{i+1}\right)
$$

where $D I_{i}, D I_{i+1}$ are the lower and upper bounds of the its limit state for the two damage indices considered, while $P\left(D I>D I_{i}\right)$ is the exceedance probability given occurrence of the earthquake for every limit state given by the following expression:

$$
P\left(D I>D I_{i}\right)=\frac{-1}{v t} \cdot \ln \left[1-P_{t}\left(D I>D I_{i}\right)\right]
$$

where $P_{t}\left(D I>D I_{i}\right)$ is the exceedance probability over a period $[0, t]$; and $t$ is the service life of a new structure or the remaining life of a retrofitted structure. In this work one year service life $(t=1)$ is considered and the annual 
exceedance probability $\bar{P}\left(D I>D I_{i}\right)$ is obtained as follows: For ordinary at least three seismic Hazard Level (63.2/50, $10 / 50$ and 2/50) based China seismic code corresponding to known annual exceedance probabilities $(2 \%, 0.21 \%$ and $0.0404 \%$, respectively), the maximum values of the DIs considered are calculated as following. Therefore, the maximum DIs calculated are calculated at each hazard level have an annual exceedance probability equal to that of the current hazard level.

$$
\begin{aligned}
& \bar{P}_{50 \%}=1.39 \% \Leftrightarrow \theta_{\max 50 \%}=1.8 \times 10^{-1} \% \\
& \bar{P}_{10 \%}=2.10 \times 10^{-1} \% \Leftrightarrow \theta_{\max 10 \%}=3.31 \times 10^{-1} \% \\
& \bar{P}_{2 \%}=4.04 \times 10^{-2} \% \Leftrightarrow \theta_{\max 2 \%}=1.685 \%
\end{aligned}
$$

A nonlinear regression is fitted firstly in Yinchuan region of western China based China seismic code and site survey in this research shown in Eqs.11.

$$
P_{i}\left(\theta>\theta_{i}\right)=\gamma\left(\theta_{i}\right)^{-k}
$$

where $\gamma=0.0011, k=1.4063$ after regression nonlinear calculation. The results of EDPs corresponding to all 7 Hazard Level (HL) are shown in Fig.2.

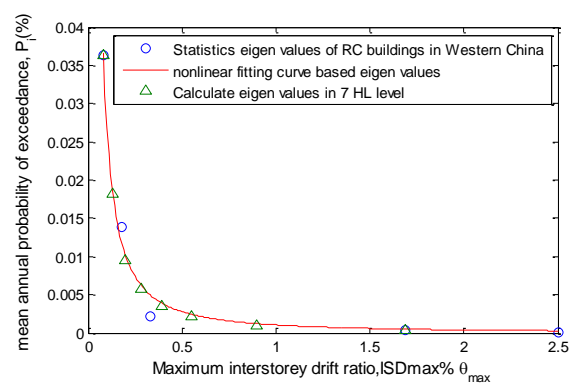

Figure 2. The regression fitting curve for calculating the median $\mathrm{ISD}_{\max } \%$ for the ith HL based China seismic code

\section{LIFE-CYCLE SEISMIC HAZARD MODEL}

Predictable ground motions in the special site firstly are considered in research as outer excitation to test structural system's performance. The life-cycle model of a seismic hazard specifies (1) the random arrival times, $T_{1}, T_{2}, L$, of individual events at a site during a reference period $\tau$, and (2) the random properties of the ground motion hazards under considerations at $T_{1}, T_{2}, L$. The random properties involves: stochastic quantification of the earthquake intensity measure (IM) based precious activity matrix at the site and creating stochastic ground motions consistent with the intensity hazard.

Monte Carlo algorithms can be used for generating samples of lifetime seismic hazard at a given site during a reference period $\tau$. Therefore, a life-cycle hazard sample consists of the arrival times of individual events and the properties defining their probability law.
The activity matrix of seismic hazard at a given site delivers the annual rate of occurrence for events of the hazard corresponding to earthquake magnitude $M$ and rupture distance $r$. We can plot activity matrices against the properties which completely define the probability law of the hazard at the site. The plot of mean annul rate of occurrence of earthquake for all $(M, r)$ at the site is called the site seismic activity matrix.

The average number of events per year irrespective of the values of $(M, r)$ is

$$
v=\sum_{i=M, r} v_{i_{M}, i_{r}}
$$

We assume that the events in time according to a homogeneous Poisson counting process $\{N(\tau), \tau \geq 0\}$ of intensity $v$ so that

$$
P(N(\tau)=n)=\frac{(v \tau)^{n}}{n !} \exp (-v \tau), \quad n=0,1,2, \ldots
$$

The approach corresponds to a 'source-based' stochastic ground motion model, developed by considering the physics of the fault rupture at the source as well as of the propagation of seismic waves through the entire ground medium till the structural site. It is based on a parametric description of the ground motion's radiation spectrum $A(f ; M ; r)$, dependent on the earthquake magnitude $M$ and rupture distance $r$ and expressed as a function of the frequency $f$.This spectrum consists of many factors that account for the spectral effects from the source (source spectrum) as well as propagation through the earth's crust. The duration of the ground motion is addressed through an envelope function $e(t ; M ; r)$, which is also depends on $M$ and $r$. More details on them are shown in article [2]. These frequency and time domain function $A(f ; M ; r)$ and $e(t ; M ; r)$, completely describe the model and their characteristics are provided by predictive relationships that relate them directly to the seismic hazard such as $M$ and $r$.

The activity matrix of seismic hazard at a given site delivers the annual rate of occurrence for events of the hazard corresponding to earthquake magnitude $M$ and rupture distance $r$, which completely define the probability law of the hazard at the site. The plot of mean annual rate of occurrence of earthquake for all $(M, r)$ at the site is called the site seismic activity matrix. In this work buildings located in Yinchuan region in western China are chosen because of high seismic hazardous of local region. Seven hazard levels (HL: 72/50, 38/50, 25/50, 16/50, 10/50, 5/50, $2 / 50$ ) corresponding to the different annual probability of exceedance and maximum inter-storey drift ratio in local area are calculated based China seismic code and shown in Tab1. Therefore, the maximum DIs calculated at each hazard 
level have an annual exceedance probability equal to that of the current hazard level (HL).
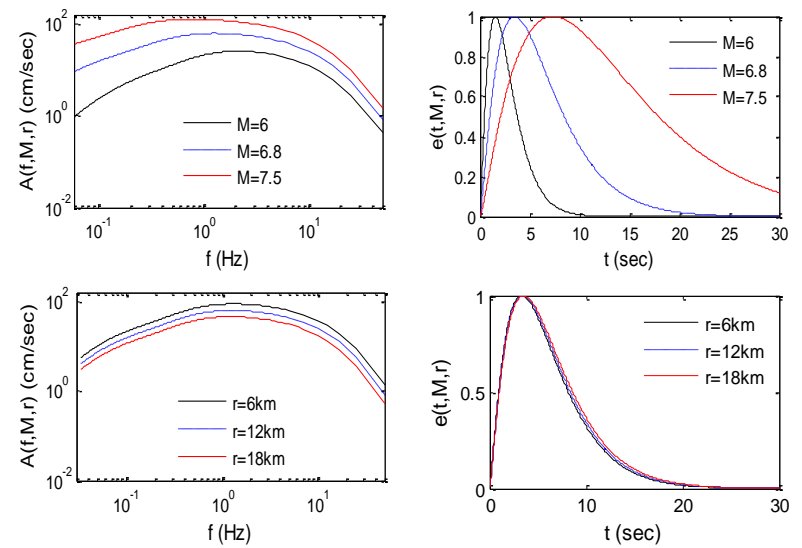

Figure 3. Envelopes with different earthquake magnitude and rupture distance
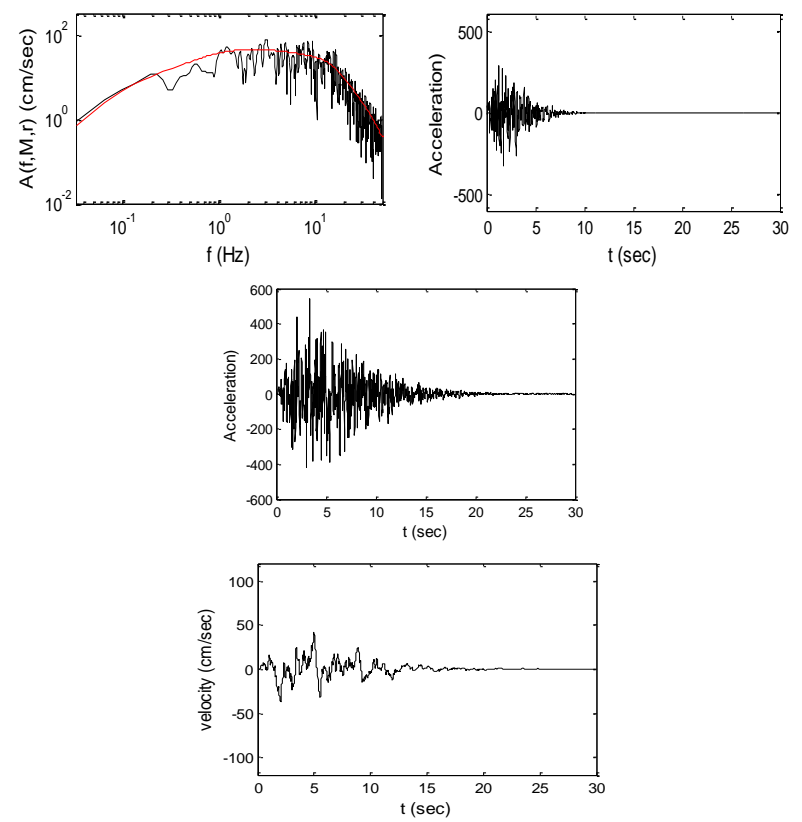

Figure 4. A sample wave of stochastic ground motions

TABLE I. Seismic Damage Median Eigen Values of RC Frame

\begin{tabular}{|c|c|c|c|c|c|c|c|}
\hline$P_{50 \%}$ & 72 & 38 & 25 & 16 & 10 & 5 & 2 \\
\hline $\bar{P}_{i}$ & 2.51 & 0.95 & 0.57 & 0.35 & 0.21 & 0.10 & 0.04 \\
\hline$\theta_{\max }$ & 0.10 & 0.20 & 0.28 & 0.39 & 0.55 & 0.90 & 1.69 \\
\hline $\mathrm{LS}$ & $\mathrm{S}$ & $\mathrm{LI}$ & $\mathrm{LII}$ & $\mathrm{MI}$ & $\mathrm{MII}$ & $\mathrm{H}$ & $\mathrm{Ma}$ \\
\hline
\end{tabular}

\section{Simple RC Buildings Model B ased China Code}

For the calculate example, the simple six storey reinforced concrete building used in this research. The structure corresponds to towns' and villages' RC buildings wide used in Western China comply with the China seismic code (GB50011-2010) [3].

In this work, RC 3D moment resisting framed buildings have been considered in order to obtain the seismic insurance model and influence of various sources of uncertainties on the life-cycle cost. Steel of class with yield stress of $335 \mathrm{Mpa}$ and modulus of elasticity equal to 210Gpa has been considered, while concrete of cubic strength of $25 \mathrm{Mpa}$ and modulus of elasticity equal to $30 \mathrm{Gpa}$. The structural layout of the building represents six bays in longitudinal direction with $6-8 \mathrm{~m}$ span lengths and three bays in transverse direction with 6-2.5-6m span lengths respectively. The storey height is $3.3 \mathrm{~m}$. The column elements size is $0.5 \mathrm{~m} \times 0.5 \mathrm{~m} \sim 0.5 \mathrm{~m} \times 0.7 \mathrm{~m}$. The beam size is $0.25 \mathrm{~m} \times 0.6 \mathrm{~m}$. The slab thickness is equal to $12 \mathrm{~cm}$, while in addition to the self weight of the beams and the slabs, a distributed permanent load of $2 \mathrm{kN} / \mathrm{m}^{2}$ due to floorfinishing partitions and live load of $1.5 \mathrm{kN} / \mathrm{m}^{2}$. For the analysis a three dimensional fiber model is created in Seismostruct software shown in Fig.5.

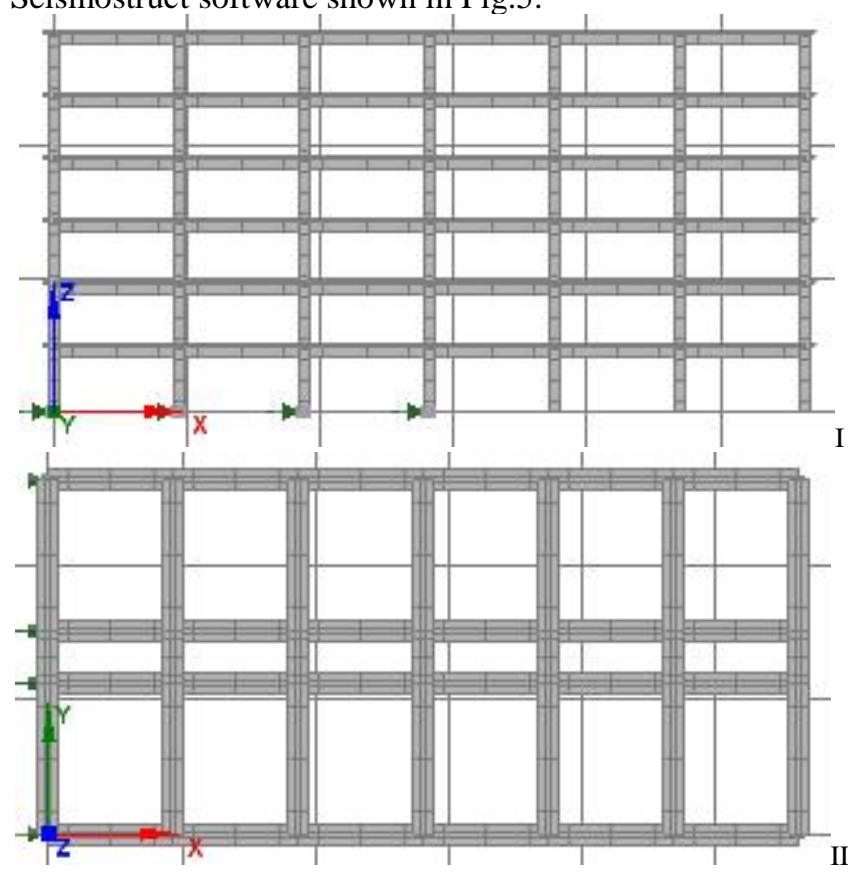

Figure 5. The representative $\mathrm{RC}$ frames: (i) front view and (ii) plan view

\section{INCREMENTAL ANALYSES}

In the seismic assessment of structures a wide range stochastic man-made waves and seven performance level be considered in order to take into account the uncertainties. The main objective of a IDA method is to define a curve through a relation between the seismic intensity level and the corresponding maximum response of the structural system. The intensity level and the structural response are described through an intensity measure (IM) and an engineering demand parameters (EDP) which refers also as damage index (DI). Incremental analysis are implemented through the following steps in this research: (i) Construct 
the local typical digital finite element model for performing nonlinear dynamic analyses; (ii) select a group of stochastic man-made waves fitted with local response spectrum; (iii) select a proper intensity measure and an engineering demand parameter; (iv) employ an appropriate algorithm for selecting the record scaling factor in order to obtain the IMEDP curve by performing the least required nonlinear dynamic analyses and (v) employ a summarization technique for exploiting the multiple waves results. In this work, the $S_{a}\left(T_{1}, 5 \%\right)$ for damping equal to $5 \%$ is selected as IM indicator, since it is the most commonly used intensity measure in practice today for the analysis of buildings. At the same time, two kind of damage index: the maximum inter-storey drift $\theta_{\max }$ and maximum floor acceleration are chosen as EDPs, which are based on the maximum deformation of different damage state.

Actually scale factor is a key setting through IM in incremental analysis. The maximum inter-storey drift is recommended by FEMA-350 as the most suitable performance criterion for frame structures and is used in this study [4]. Depending on the problem and the performance that is needed to be calculated different intensity measures and performance factors can also be used. In this work two types of scaling be used: scaliing all ground motion records in the same value of spectral acceleration. or using a common scaling factor for all ground motion records. The $S_{a}\left(T_{1}, 5 \%\right)$ is calculated from the hazard curve of the area of interest, such as Yinchuan of western China in this work shown in Fig.6.

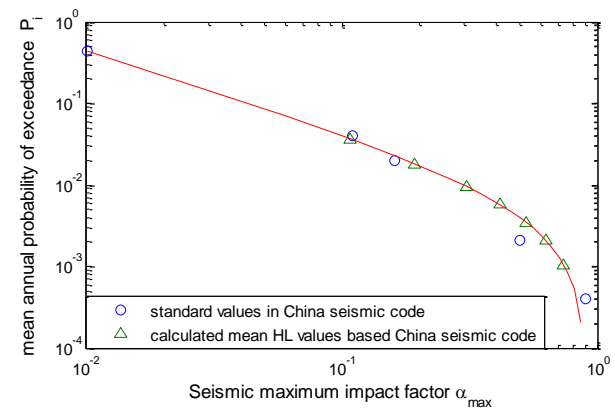

Figure 6. The regression fitting curve for calculating the earthquake impact factor amax for the ith HL based China seismic code

$P_{50 \%}$ is the exceedance probabilities in 50 years, and corresponding to known annual exceedance probabilities in Table II.

TABLE II. IMPACT FACTOR MEdian VALUES IN YinChUAN

\begin{tabular}{|c|c|c|c|c|c|c|c|}
\hline$P_{50 \%}$ & 72 & 38 & 25 & 16 & 10 & 5 & 2 \\
\hline $\bar{P}_{i}$ & 2.513 & 0.951 & 0.574 & 0.348 & 0.21 & 0.103 & $\begin{array}{c}0.040 \\
4\end{array}$ \\
\hline$\alpha_{\max }$ & 0.148 & 0.307 & 0.415 & 0.525 & 0.627 & 0.739 & 0.824 \\
\hline
\end{tabular}

For example actual physical damage calculation process of RC frames using IDA with Friuli Italy-02 (1976) earthquake record is explained next carefully. The IM scale factor increase from 1 to 9 in IDA analysis. The whole damage results of maximum inter-storey drift ratio and maximum floor acceleration of every storey are shown in Fig.7. That means all kind of seismic intensity waves have impacted on RC buildings in life-cycle period. So the structural and non-structural damage of every floor of RC buildings can be calculated from the two EDPs parameters. The maximum ISD\% of whole structure locates in second floor and the maximum floor acceleration (MFA) in the top floor at the same time. So that mean the most structural damage lie in second floor and the severe non-structural damage in top storey. The tendency of the seismic vulnerability changed more obvious than ever.

The relation between the drift ratio limits with the limit state. employed in this study is partly based on the work of Ghobarah [5] for ductile RC moment resisting frames, and at the same time vast stochastic sampling based Monte Carlo method based local construction code in Western China also impact the limit state setting in this research. The relation of the limit state with the values of the floor acceleration is partly based on the work of Elens and Meskouris [6].
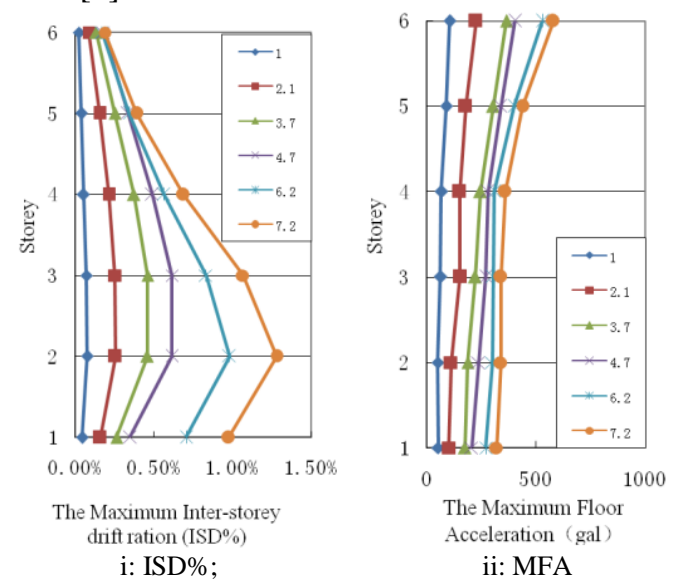

Figure 7. The maximum inter-storey drift ratio and maximum floor acceleration in IDA for Friuli Italy-02

TABLE III. DRIFT RATIO AND FLOOR ACCELERATION LIMITS FOR RC MOMENT Resisting Frames in YinCHUAN OF WeSTERn CHINA

\begin{tabular}{|c|c|c|}
\hline Limit State & $\theta_{i s d}(\%)$ & $a_{\text {floor }}(g)$ \\
\hline (I)--None & $\theta \leq 0.1$ & $a \leq 0.05$ \\
(II)-Slight & $0.1<\theta \leq 0.2$ & $0.05<a \leq 0.10$ \\
(III)-Light & $0.2<\theta \leq 0.28$ & $0.10<a \leq 0.16$ \\
(IV)-Light II & $0.28<\theta \leq 0.4$ & $0.16<a \leq 0.20$ \\
(V)-Moderate I & $0.40<\theta \leq 0.55$ & $0.20<a \leq 0.30$ \\
(VI)-Moderate II & $0.55<\theta \leq 0.90$ & $0.30<a \leq 0.50$ \\
(VII)-Heavy & $0.90<\theta \leq 1.70$ & $0.50<a \leq 0.75$ \\
(VIII)-Major-Ma & $\theta>1.70$ & $a>0.75$ \\
\hline
\end{tabular}




\section{LIFE-CYCLE SEISMIC COST ASSESSMENT \& CONCLUSION}

The life-cycle seismic cost can be obtained finally through incremental dynamic analyses based above Eqs.(1)(9).

A more detailed description of the different cost evaluation for each limit state cost can be found in Tab IV. The basic cost mentioned in Table IV refers to the first component of the calculation formulas. While they are given in monetary units (RMB). The values of the mean damage index, loss of function, down time, expected minor injury rate, expected serious injury rate and expected death rate used in this study are based on [7-8]. Death rate denotes the number of persons that may die at a specific limit state and it is defined as the number of occupants $\times$ death rate. Table $\mathrm{V}$ provides the revised limit state parameters of cost evaluation in this work on the base of FEMA-227 limit state dependent damage consequence severities.

After study local statistics data of construction engineering in Yinchuan, it located in high seismic hazardous region of western China. In this research $2500 \mathrm{RMB} / \mathrm{m}^{2}$ is considered as $C_{I N}$, meantime $\pm 10 \%$ variance is also included.

TABLE IV. LIMIT STATE COSTS-CALCULATION FoRMULA

\begin{tabular}{|c|c|}
\hline Cost Category[9] & Basic Cost \\
\hline Damage/repair $\left(C_{d a m}\right)$ & $1200 \mathrm{RMB} / m^{2}$ \\
\hline Loss of contents $\left(C_{c o n}\right)$ & $300 \mathrm{RMB} / m^{2}$ \\
\hline Rental $\left(C_{r e n}\right)$ & $20 \mathrm{RMB} / \mathrm{month} / m^{2}$ \\
\hline Income $\left(C_{i n c}\right)$ & $400 \mathrm{RMB} /$ year/ $m^{2}$ \\
\hline Minor Injury $\left(C_{i n j, m}\right)$ & $2000 \mathrm{RMB} /$ person \\
\hline Serious Injury $\left(C_{i n j, s}\right)$ & $2 \times 10^{4} \mathrm{RMB} /$ person \\
\hline Human fatality $\left(C_{f a t}\right)$ & $8 \times 10^{5} \mathrm{RMB} /$ person \\
\hline
\end{tabular}

*Occupancy rate $30 \mathrm{~m}^{2} /$ person based China government rules

TABLE V. LIMTT STATE PARAMETERS FOR COST ESTIMATION

\begin{tabular}{|c|c|c|c|c|}
\hline \multirow{2}{*}{$\begin{array}{c}\text { Limit } \\
\text { State }\end{array}$} & \multicolumn{4}{|c|}{ Calculate index based FEMA-227 [7] } \\
\cline { 2 - 5 } & $\begin{array}{c}\text { Mean } \\
\text { damage } \\
\text { index \% }\end{array}$ & $\begin{array}{c}\text { Expected } \\
\text { minor } \\
\text { injury rate }\end{array}$ & $\begin{array}{c}\text { Expected } \\
\text { serious } \\
\text { injury rate }\end{array}$ & $\begin{array}{c}\text { Expected } \\
\text { death rate }\end{array}$ \\
\hline N & 0 & 0 & 0 & 0 \\
S & 0.5 & $3.0 \times 10^{-5}$ & $4.0 \times 10^{-6}$ & $1.0 \times 10^{-6}$ \\
LI & 2 & $1.3 \times 10^{-4}$ & $1.8 \times 10^{-5}$ & $0.4 \times 10^{-5}$ \\
LII & 5 & $3.0 \times 10^{-4}$ & $4.0 \times 10^{-5}$ & $1.0 \times 10^{-5}$ \\
MI & 9 & $1.4 \times 10^{-3}$ & $1.6 \times 10^{-4}$ & $0.4 \times 10^{-4}$ \\
MII & 20 & $3.0 \times 10^{-3}$ & $4.0 \times 10^{-4}$ & $1.0 \times 10^{-4}$ \\
H & 45 & $3.0 \times 10^{-2}$ & $4.0 \times 10^{-3}$ & $1.0 \times 10^{-3}$ \\
Ma & 80 & $3.0 \times 10^{-1}$ & $4.0 \times 10^{-2}$ & $1.0 \times 10^{-2}$ \\
\hline
\end{tabular}

Loss of

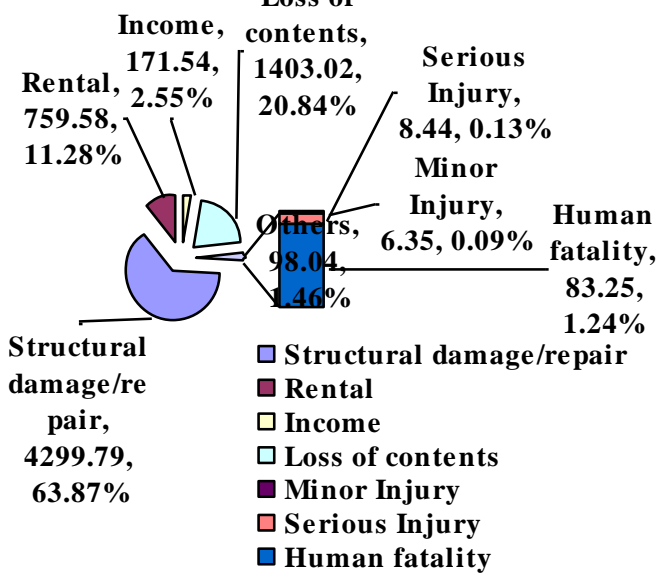

Figure 8. The constitution of RC buildings' LCC in Yinchuan region
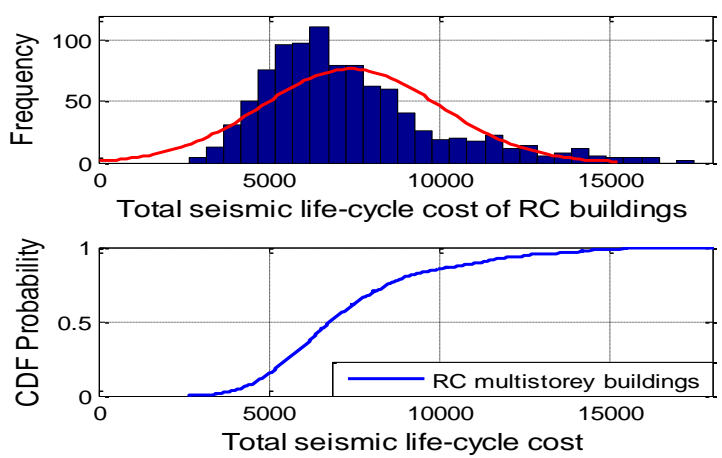

Figure 9. The column diagram probability and cumulative distribution curve

The statistics median covered area of typical sample RC building is $3600 \mathrm{~m}^{2}$. The annual average LCC is $2.06 \mathrm{RMB} / \mathrm{m}^{2}$ after calculation using above procedure, and annual median LCC is $1.89 \mathrm{RMB} / \mathrm{m}^{2}$. There will add up additional reasonable $50 \%$ fee if insurance companies will establish catastrophe insurance in the near future. The final insurance payment per people is about $85-92.7 \mathrm{RMB}$ every year in considering of local life endurance in this research on base of average living space per person equal $30 \mathrm{~m}^{2}$. The result is lying in acceptable level for local people in Yinchuan city of western China as research sample region finally.

\section{ACKNOWLEDGMENT}

The first author acknowledges the financial support of the National Natural Science Foundation of China (No.51468050) and the China postdoctoral Science Foundation.

\section{REFERENCES}

[1] Porter KA, Kiremidjian A S, LeGrue J S., "Assembly-based vulnerability of buildings and its use in performance evaluation," Earthquake Spectra, vol.18, pp.291-312, 2001. 
[2] Boore DM. Simulation of ground motion using the stochastic method. Pure Appl Geophys, vol.160, pp.635-676, 2001.

[3] Ministry of Construction P.R.China,"Code for seismic design of buildings (GB50011-2010)," China Construction Press Publication, Beijing, 2010.

[4] Federal Emergency Management Agency, "FEMA 350: Recommended seismic design criteria for new steel moment-frame buildings " Washington, DC, Building Seismic Safety Council, 2000.

[5] Ghobarah A., "On drift limits associated with different damage levels," Proceedings of the international workshop on performancebased seismic design, June 28-July 1, 2004.
[6] Elenas A, Meskouris K, "Correlation study between seismic acceleration parameters and damage indices of structures," Eng Struct, vol.23, pp.698-704, 2001.

[7] Federal Emergency Management Agency, "FEMA 227:A benefit-cost model for the seismic rehabilitation of buildings," Washington, DC, Building Seismic Safety Council, 1992.

[8] Z. Jian, T.Pin and Z. Fulin, "A Review of Life-Cycle Seismic Loss Estimation in Civil Engineering," Journal of vibration and shock, vol. 34, No1.7, Sep. 2015, pp.111-119, doi:10.13465/ j.cnki.jvs.2015.17.019.

[9] Wen YK, Yang YJ, "Minimum buildinglife-cycle cost design criteria II: applications" J Struct.Eng, vol.127, No.3, pp.338-346, 2001. 